\title{
NFC BASED STOCK MAINTAINANCE AND BILLING SYSTEM WITH AUTO ALERT TO CUSTOMERS
}

\author{
M.Elizabeth Sherine ${ }^{1}$, Shinu Sadeyone ${ }^{2}$ \\ ${ }^{1}$ Asst professor, EIE Department, Sathyabama University, Chennai, India \\ ${ }^{2}$ Asst professor, EIE Department, Sathyabama University, Chennai, India
}

\begin{abstract}
This paper suggest a novel automation scheme for stock and billing management in ration shops using NFC and load cell technologies. This system prevents from forgeries like, by selling the stocks belonging to one card holder to others; not providing the eligible card holders what they require. NFC Tags are provided to each customer for that particular area belonging to a shop in that area. Load cell is used to measure the correct quantity eligible for each card. The card holders will be intimated by a message using GSM technology about the arrival of every new stock in the shop every week for the whole month. Using this message, they can buy the items. Load cell is used to measure the correct weight of the items according to the card's limit. They cannot buy more than this eligible limit using the card again in the same month. Stock management is done by using two IR sensors. If the stocks pass from IR 1 to IR 2 then it denotes the selling of items and if it passes from IR 2 to IR 1 , then it represents buying of stocks for the shop. This is also verified with the weight of the stocks when sold. Each item is given a NFC Tag for easy billing process.
\end{abstract}

Keywords: NFC, IR Sensor, GSM

\section{GENERAL DESCRIPTION}

The requirement of the automated stock maintenance and billing system rose from ration shops. Goods were delivered to various ration shops in a particular quantity but after a few surveys it was concluded that the quantity delivered to the customers were quantitively less. The same amounts of goods were not delivered to the customers as of the retailers either sold a part illegally or supplied it to other private retailers at higher costs. Quiet a mass of goods were forged or sold illegally by the retailers.

The same goods that are purposed to be sold at governmental public distribution system were sold to customers by private retailers at higher costs. This problem occurrence was due to illegal supply of goods from governmental public distribution system to the private retailer. This not only caused loss of economy to the government but also caused inconvenience to the public as they were not supplied with the required amount of goods.

To keep a check over this issue this stock maintenance and billing system can prove to be a useful remedy. In this system implementation of NFC tag and reader is done. Also the load cells are provided to measure the quantity received by ration centers and the quantity delivered to customers.

This system also bears the capability of intimating the customers on arrival of new stock in the stores. The information will be provided to various customers via usage of GSM. The GSM will send text message to all its registered customers as soon as the new stock arrives.

\section{LITERATURE REVIEW}

Near-field Communication (NFC) is characterized as a short range radio communication technology with a lot of potential, especially when applied to mobile handset. In order to make the establishment of these contactless connection easier, this popular communication technology was created. NFC gateway protocol can be used for network driven services [1] and a secure authentication process to achieve a NFC m- payment system.

NFC can also be used in industries were companies producing consumer products have begun working on ways to control their products over the IP (internet protocol). Multinational electronics firms are marking a fair share of their lines using technologies like the RFID, NFC, etc a front end to the IP networks where every piece of equipment integrated is to be controlled by a central unit.

IP based systems are supposed to be simpler to be accessed and easier to manipulate, with the only necessity being, close proximity to a direct internet connection. With this in mind IP Ac Box was developed [2] which allows industrial automation systems to be accessed and controlled through a direct internet connection right out of the box even in dynamic IP configurations.

The Near Field Communication (NFC) technology provides a good opportunity to support the automated execution of several education related processes. Recently a new challenge is identified at the Budapest University of Technology and Economics. As most of the lecture notes had become available in electronic format the students especially the inexperienced freshman ones did not attend to 
the lectures significantly decreasing the rate of successful exams.

This drove to the decision to elaborate an accurate and reliable information system for monitoring the student's attendance at the lectures. Thus Benyo and his team [3] developed a novel, NFC technology based business use case of student attendance monitoring. In order to meet the requirements of the use they implemented a highly autonomous distributed environment assembled by NFC enabled embedded devices, so-called contactless terminals and a scalable backoffice. Beside the opportunity of contactless card based student identification the terminals support biometric identification by fingerprint reading. These features enable the implementation of flexible and secure identification scenarios. The attendance monitoring use case has been tested in a pilot project involving about 30 access terminals and more than 1000 students.

Near Field Communication (NFC) is a promising new communication technology that, among other things, allows mobile phones to emulate smart cards such as the travel cards used in public transportation. Bringing the travel card into mobile phone creates numerous benefits for both end users and service providers, which is why mobile ticketing with NFC technology has been considered a promising service. However, despite optimistic predictions, NFC technology and mobile ticketing services based on it, has yet to take off. While technical problems have played a part in this delay early on, the most significant reasons can be found in the challenging business models needed to realize NFC services. Thus NFC based mobile ticketing business model [4] is evaluated using a theoretical framework called the STOF model.

Want, R, in his paper entitled near field communication [5] had given a detailed note about near field communication. He proposed that for many years, pervasive computing research has explored the potential benefits of creating a connection between the virtual world of the Internet, and the physical world we live in. The Near Field Communication (NFC) standard might, at last, be the technology that makes this vision-sometimes referred to as the Internet of things-a ubiquitous reality.

\section{PROPOSED SYSTEM}

The objective of this project is to automate the ration shop using NFC, Load Cell and GSM module so that the customers can be made aware of the availability of goods as well as arrival of the new stocks in the ration shop. This system is also convenient for the retailers to keep an account on the availability of goods. This system also bears the capability of intimating the customers on arrival of new stock in the stores. The information will be provided to various customers via usage of GSM. The GSM will send text message to all its registered customers as soon as the new stock arrives. The load cells are implemented for accurate results. The items purchased by the retailer and sold by them are put into account which can be made for stock maintenance.
In this proposed system, stock and supply identification, calculation and the intimation of stock arrival to the customers are made automatic using NFC. In this system, each card holding customers of the belonging to particular areas' ration shop are provided with smart NFC card. When new stocks for ex: (sugar) arrive at the shop for the month, then using a GSM modem in the shop, a message is sent to all the customers' mobile numbers. The card holder can buy it by using the NFC tag provided to them. Each item is also provided with a NFC tag.

NFC reader in the shop reads the value, compares it with the help of microcontroller and then provides them the items by measuring their exact weight using a load cell. The card holder cannot purchase that particular item again if their limit has been crossed for that month. Also, the incoming and sold out stocks in the shop is identified using IR sensors. Once if all the items have been purchased by the customer for the month, then they cannot again purchase any items in the same month.

Also, a message is sent to the mobile number using GSM modem in the shop that all the items which are eligible for their card for the month has been purchased. By implementing this method, forgeries can be restricted to a great extent and proper supply for the needy and eligible person will be provided. We developed the system with different devices such as PIC microcontroller, a LCD display, MAX 232, load cells, a NFC tag reader and NFC tags provided to various goods respectively. After doing the connection we have installed the NFC tags on the sample goods. Now by using the NFC reader we will scan each NFC tag provided with the respective goods. Each time NFC tag reads a data LCD module will display the details of the particular item. The NFC is used to read the available and purchased items and correspondingly the load cell provides the exact quantity of the particular item.

The data's from NFC will be stored for future reference and documentation of the amount of goods available and sold. The microcontroller is programmed to control all this activities. The GSM module is used to provide the details of available stocks and commodities to the consumer.

The PIC Microcontroller is the heart of the system which controls the entire process effectively. Microcontroller manages and controls the functioning of IR sensor, NFC, and GSM module. 


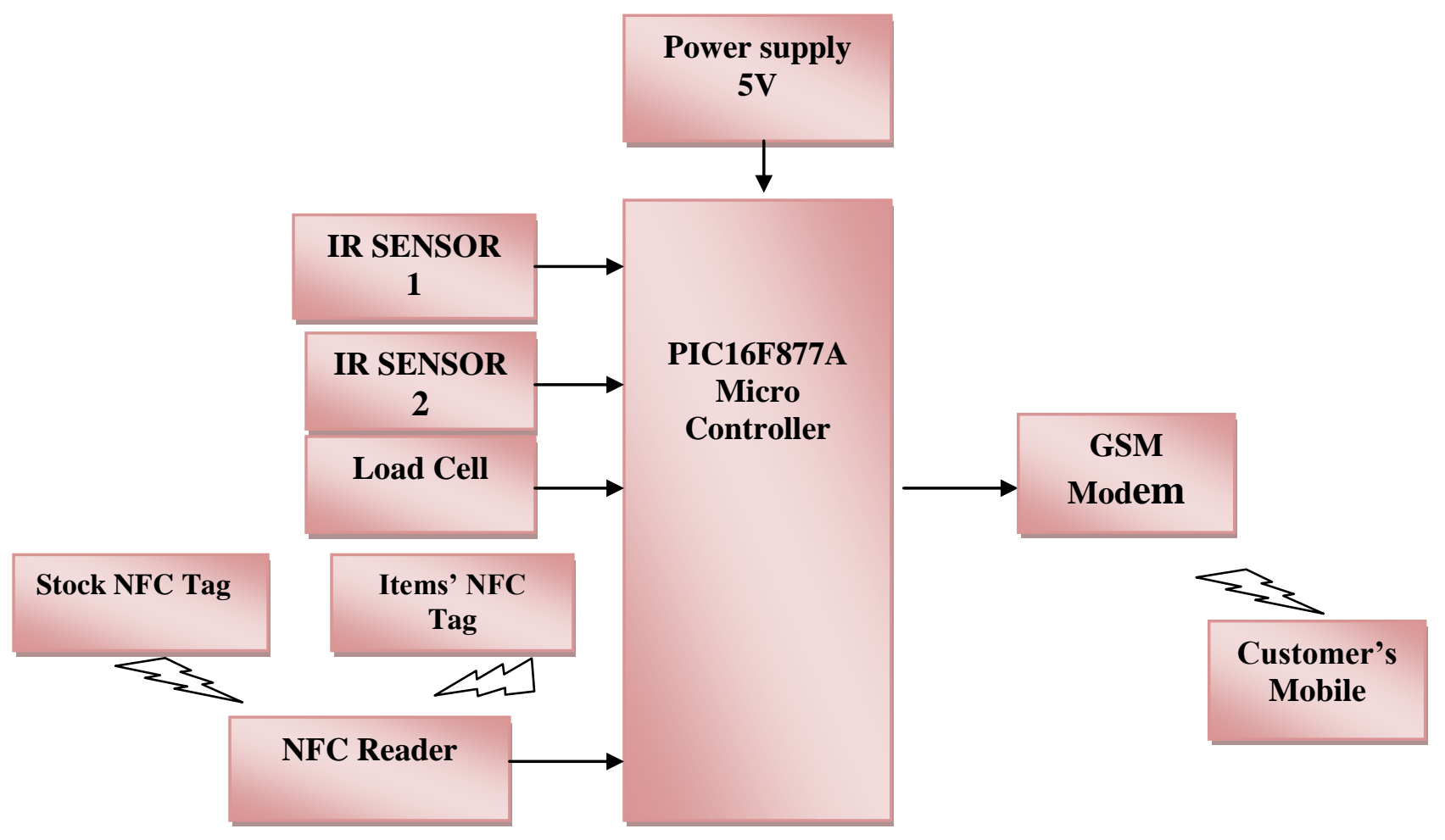

Fig-1 Block Diagram

The block diagram for this proposed system is shown in Fig1. The main components of this system are PIC Microcontroller, Load cell, NFC Tag, IR Sensor and GSM modem. The IR sensor1 senses the arrival of the items and send a signal to the micro controller. The micro controller forecasts this information to the consumer by using GSM module as well as the item arrival is also entered in the stock. IR Sensor2 is used to know the items dispatched to the consumer when an item is delivered to the customer the same amount will be reduced from the stock. For measuring the weight of items available in stock and to know the weight of items dispatched the load cell is used. Load cell senses the weight of items and gives the information to the microcontroller for stock maintenance. NFC tag is provided to each customer in that particular area. There will be separate tag for each item. Once the items arrived in ration shop the message will be send to the consumer and he can purchase the particular item by using the particular tag. The NFC reader in the shop will sense the consumers NFC tag and provides the particular item to him. Consumer will have separate NFC tags for stock as well as for the items to be purchased.

\section{NFC}

Near Field Communication (NFC) is a new short-range, standards-based wireless connectivity technology, that uses magnetic field induction to enable communication between electronic devices in close proximity. Based on RFID technology, NFC provides a medium for the identification protocols that validate secure data transfer. NFC enables users to perform intuitive, safe, contactless transactions, access digital content and connect electronic devices simply by touching or bringing devices into close proximity.

Near field communication (NFC) is a set of standards for smart phones and similar devices to establish radio communication with each other by touching them together or bringing them into proximity, usually no more than a few inches. Present and anticipated applications include contactless transactions, data exchange, and simplified setup of more complex communications such as Wi-Fi. Communication is also possible between a NFC device and an unpowered NFC chip, called a "tag". NFC standards cover communications protocols and data exchange formats, and are based on existing radio-frequency identification (RFID) standards including ISO/IEC 14443 and FeliCa. The standards include ISO/IEC 18092 and those defined by the NFC Forum, which was founded in 2004 by Nokia, Philips Semiconductors (became NXP Semiconductors since 2006) and Sony, and now has more than 160 members. The Forum also promotes NFC and certifies device compliance and if it fits the criteria for being considered a personal area network.

\section{RESULTS AND DISCUSSION}

In this paper an innovative way to automate the ration shop is proposed. We have used NFC reader instead of RFID which enhances a faster and accurate result than RFID. Moreover GSM modem is incorporated which facilitates the consumer by providing the availabity of the items without waiting in the queue for a long time. As an advantage, by using load cell and IR sensors accurate weight of the items in the stock as well as that supplied to the consumer is guaranteed. Moreover the forgeries in the ration shop can be reduced to minimal. 
The hardware designed for this purpose was shown below:

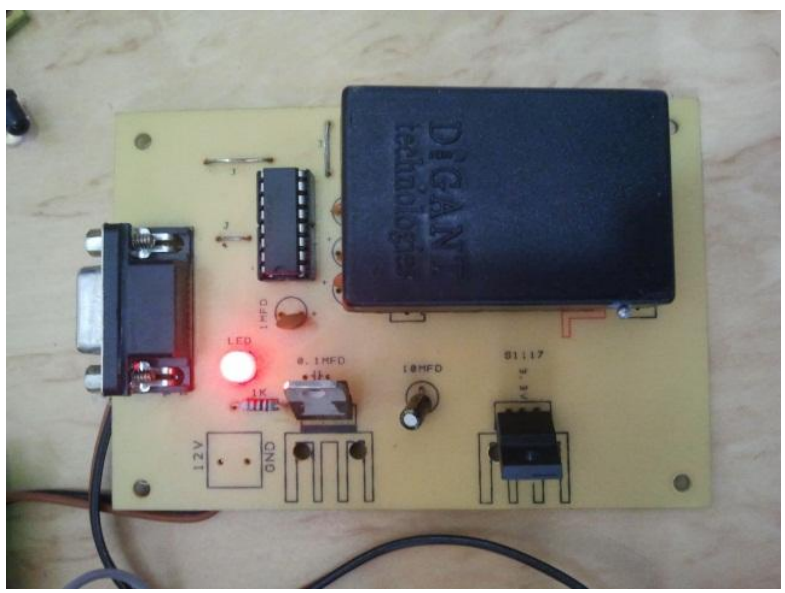

Fig-2 GSM Board

Fig-2 indicates a GSM Module which sends message to the customer according to the signal from the microcontroller.

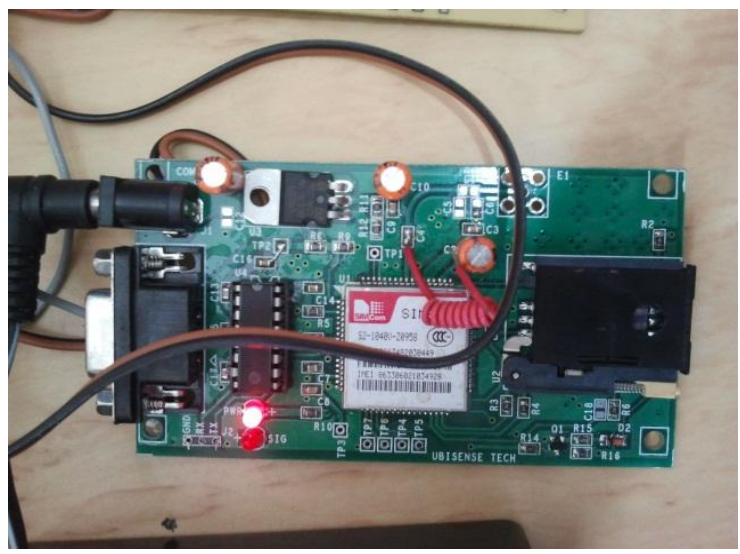

Fig-3 GSM Reader

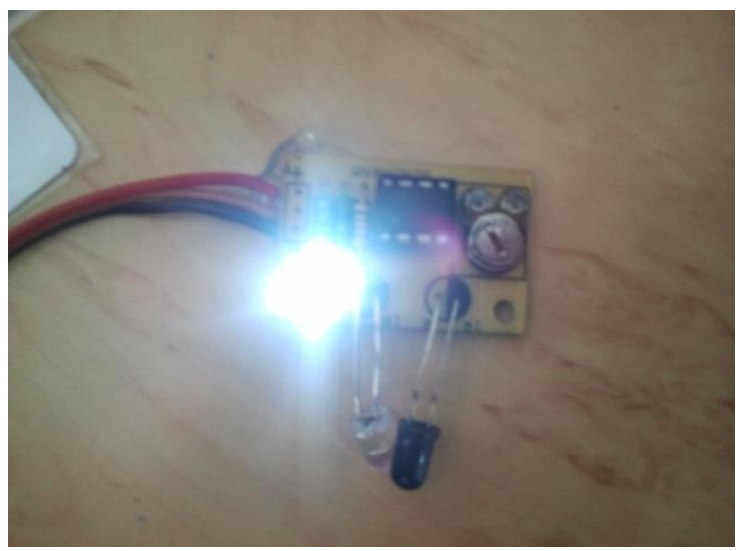

Fig-4 IR Sensor

Fig-4 shows a IR sensor1 which gives the information about the stock purchased for the ration shop.

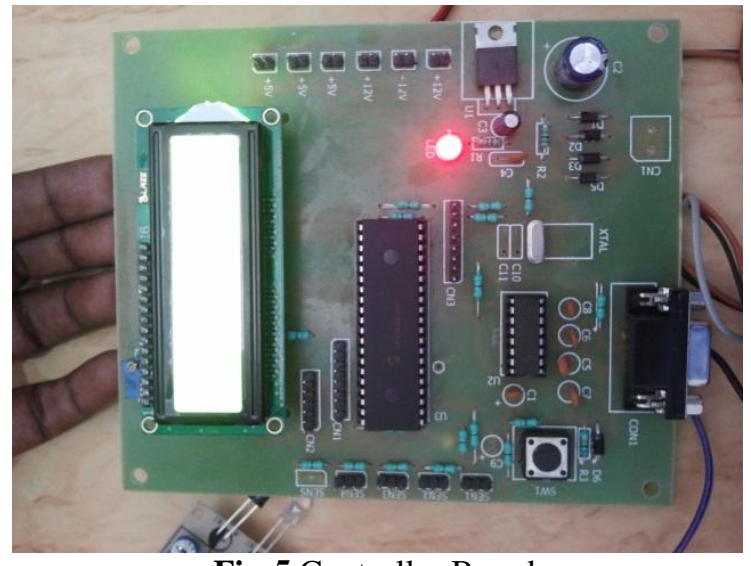

Fig-5 Controller Board

Fig-5 shows the controller board which is the information provider and process controller for the whole system

\section{CONCLUSIONS}

From the results, we have determined that load cell weighing technique is superior to the conventional electronic weighing machine. The NFC system has an ace over the RFID as it has a faster response with an enhanced accuracy. The ease of usage also makes it more practical for implementation. The system is convenient for the retailers to keep an account on the availability of goods. The system also proves worthy for the customers as they are awarded about the goods available in the stock. The customers will not need to queue up in ration shop for hours as the can approach the centers only on intimation. Thus the proposed simplifies the purchase and delivery of the items moreover it is properly documented. Thus the entire process is automated which saves the consumers precious time by saving them from waiting in the queue for long time and makes the consumer up-to-date about the availabity of items in the ration shop.

\section{FUTURE WORK}

This automated system can be incorporated along with RFID secured system to employ more precise record of the incoming stock in the ration shop. When RFID is implemented along with NFC this system will make ease of communication between the consumer and the retailer or the ration shop.

\section{REFERENCES}

[1]. Ali, T.; Awa 1, M.A ., "Secure mobile communication in m-payment system using NFC technology", IEEE International conference on Informatics, Electronics \& Vision (ICIEV), 2012.

[2]. Alkar, A. Z. ; Roach, J. ; Baysal, D., "IP based home automation system", IEEE Transactions on Consumer Electronics, Volume: 56 , Issue: 4 , Publication Year: 2010 , Page(s): $2201-2207$.

[3]. Benyo, B. ; Sodor, B. ; Doktor, T. ; Fordos, G.," Student attendance monitoring at the university using NFC", IEEE Conference Publications, 2012. 
[4]. Juntunen, A. ; Luukkainen, S. ; Tuunainen, V.K.,"Deploying NFC Technology for Mobile Ticketing Services - Identification of Critical Business Model Issues", Mobile Business and Ninth Global Mobility Roundtable (ICMB-GMR), Ninth International IEEE Conference ,2010. [5]. Want, R," Near field communication", Pervasive Computing, IEEE (Volume:10, Issue: 3 ), IEEE Computer Society, 21 July 2011.

\section{BIOGRAPHIES}

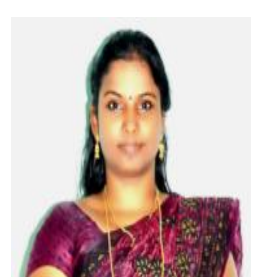

M. Elizabeth Sherine has obtained her B.E degree from Anna University Chennai in 2006. She has obtained her M.E degree from Anna University Chennai in 2012. Presently she is working as a asst.professor in Sathyabama University. Her areas of interests are sensors and transducers, embedded system and image processing.

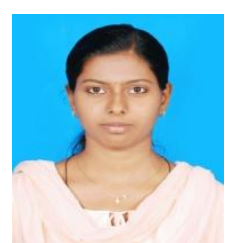

Shinu Sadeyone has obtained her B.E degree from Sathyabama University in 2011. She has obtained her M.E degree from Anna University Chennai in 2013. Presently she is working as a asst.professor in Sathyabama University. Her areas of interests are industrial instrumentation, and Image processing. 